\title{
Chapter 9 \\ Criminalisation, Health, and Labour Rights Among Im/migrant Sex Workers Globally
}

\author{
Bronwyn McBride and Trachje Janushev
}

\section{Background}

Globally, workers often migrate seeking improved working conditions, yet frequently face precarious labour and insecure employment in destination settings [1-3]: evidence from Global Northern and Southern contexts has documented unsafe working conditions, low access to labour protections, barriers to health access, and poor health outcomes among immigrant and migrant (im/migrant ${ }^{1}$ ) workers [4-7]. Im/migrants frequently face economic marginalisation, discrimination and racism, precarious immigration status, non-recognition of foreign credentials and training, and exclusion from formal employment opportunities $[5,7,8]$, all of which contribute to their over-representation in precarious, insecure, and informal forms of labour, including sex work [2, 9-11].

Precarious labour is a multidimensional construct encompassing dimensions such as employment insecurity, low wages and economic deprivation, limited social protection and workplace rights, and powerlessness to exercise workplace rights

\footnotetext{
${ }^{1}$ Because the term 'migrant sex worker' is often understood only to mean sex workers who do not hold citizenship or permanent residency (i.e. undocumented sex workers or those on temporary visas), we use the term 'im/migrant sex worker' to reference all persons (regardless of legal or immigration status) who have travelled outside of their country of origin and now do sex work in destination settings.
}

B. McBride $(\square)$

Centre for Gender and Sexual Health Equity, Vancouver, BC, Canada

Interdisciplinary Studies Graduate Program, University of British Columbia,

Vancouver, BC, Canada

e-mail: bronwyn.mcbride@cgshe.ubc.ca

T. Janushev

The Red Edition - Sex Work Migrant Group, Vienna, Austria

e-mail: t.janusev@yahoo.com 
[12]. Im/migrant workers globally are vulnerable to facing precarious labour and precarious jobs (i.e. domestic work, farm labour, sex work, temporary work) due to their lack of citizenship rights in destination countries [5, 8, 13-15].

The labour issues faced by marginalised im/migrants, such as poor working conditions, exploitation, and inadequate access to protections, are exacerbated among im/migrant sex workers due to criminalisation and stigma. The exclusion of both $\mathrm{im} /$ migrants and sex workers from access to recourse for labour rights violations enjoyed by citizens and workers in other sectors contributes to the conditions of sex work being highly precarious among this group [16, 17]. Thus, im/migrant sex workers frequently face significant precarity based on im/migrant status, sex work involvement, and criminalisation, with resulting negative implications for their occupational conditions $[16,18]$.

Historically, anti-trafficking research and discourse have conflated sex trafficking (forced sexual labour) with sex work (consensual exchange of sex services) among im/migrant groups. This contributes to the predominant misconception that racialised im/migrants (and particularly women) are inevitably involved in sex work as victims who are coerced into sexual labour [19-22]. Broader research, however, reveals that im/migrant sex workers are gender-diverse, including women, men, trans, and non-binary sex workers; highly heterogeneous, and exercise agency and autonomy in their work, which is largely overlooked [23-25]. Evidence has shown that many im/migrant sex workers travel to destination countries through legal channels, without prior sex work experience, and without experiencing coercion, but engage in sex work as a way of meeting their financial and other goals in the context of facing overlapping forms of structural exclusion $[9,22,26,27]$. In particular, community-based research suggests that sex work provides key flexibility and income for im/migrant women facing marginalisation and barriers to accessing formal employment opportunities $[9,26]$.

In contrast to common representations of im/migrant sex workers as passive victims, current research and community reports highlight im/migrant sex workers as diverse, resilient, active, and goal-oriented workers [22, 26, 28]. However, im/ migrant sex workers can be more vulnerable to labour abuses due to the limited labour protections accessible to them, shaping their health risks, access to services, and health outcomes. To date, the majority of research involving im/migrant sex workers has focused around HIV/STI risk, with a significant dearth of evidence on their work environments and access to health and other services. To further elucidate the documented structural barriers faced by im/migrant sex workers and how their socio-legal exclusion shapes labour conditions, health, and rights, the second author undertook community consultations on behalf of migrant sex worker organisation Red Edition. These consultations took the form of focus group discussions with im/migrant sex workers in Austria and inform the focus and themes described in this chapter. The methodology for these community consultations and participant demographics is presented in Box 9.1. 


\section{Box 9.1 Community Consultation Methodology and Participant Demographics}

The second author, who works with community organisation The Red Edition and holds extensive experience in sex worker and im/migrant rights advocacy, organised two focus group discussions with ten gender-diverse im/migrant sex workers working in Austria. The focus groups took place in Vienna in February 2019. The second author opened the discussion by asking openended questions to encourage conversation among participants. The focus group discussions revolved around three primary topics: legal and immigration status (i.e. knowledge of immigration laws, visa application processes, and criminal laws); labour rights issues (i.e. working conditions, laws regulating sex work, participants' lived experiences with work and relationships); and access to health services (i.e. gaps in services and needs for communityled services, discrimination in healthcare settings, and experiences with safe spaces for im/migrant sex workers [e.g. drop-in centres]).

Five participants identified as transgender, four as cisgender male, and one as cisgender female. Participants were aged 22-43, and all worked in indoor settings including studios, hotels, clients' homes, and private apartments/ homes. Participants originated from central and eastern Europe, and from central and South America.

The following thematic sections are informed by both the Red Edition community consultations and our literature review. In these sections, we introduce the multilevel structural determinants influencing im/migrant sex workers' health and labour by presenting literature findings and participant quotes from community consultations. We also present policy and programmatic recommendations based on epidemiological evidence, qualitative research, and im/migrant sex worker voices from the community consultations and across the globe on the subject of enhancing their health and rights.

\section{Intersection of Sex Work Laws and Immigration Policies: A Dual Burden of Criminalisation}

Previous literature from North America, Latin America, and Europe has highlighted the issue of prohibitive sex work and immigration laws, which result in a dual burden of criminalisation among im/migrant sex workers who are not citizens [16, 25, 28-30]. Even in New Zealand, where sex work is fully decriminalised for New Zealand citizens, im/migrants are explicitly prohibited from engaging in sex work and continue to be criminalised [31].

In the community consultations conducted on behalf of Red Edition for this chapter, participants described how, in Austria, the right to legally engage in sex work is 
linked to the right to legally stay in the country. Sex work remains criminalised among im/migrants from non-EU countries, including those who hold residence permits in other EU countries. Furthermore, sex workers living with HIV are criminalised in Austria: even individuals adhering to ART and with undetectable status are not allowed to engage in sex work. Such restrictive immigration and labour policies render sex work by non-EU im/migrant sex workers illegal, and subject those workers to enhanced policing, discrimination, and social marginalisation.

When non-EU im/migrant sex workers sought recourse for labour or housing issues, they were often met with discriminatory treatment from police based on their im/migrant status:

I was kicked out from my apartment even though I already paid my rent, and I went to the first police station to ask for help. The police officer understood everything I said in English, but he continued to speak with me in German! I felt really bad.-focus group participant

Even in circumstances where they were facing violence or labour rights violations, participants in the consultations said that fear of criminalisation and potential immigration status revocation often discouraged them from accessing police protections. While many im/migrants' fears of criminalisation stemmed from limited knowledge of the laws regulating sex work and immigration, participants also reported a high level of sharing of experiences and information among their peers, and a strong sense of solidarity in managing the burden of criminalisation.

\section{Prohibitive Laws: Protecting Im/migrants or Punitive Enforcement?}

Participants' experiences reflect the dual burden of criminalisation faced by im/ migrant sex workers in many settings, due to the criminalisation of sex work and im/ migrant status. In some settings where selling sexual services is legal among citizens, it remains criminalised among some types of labour im/migrants [16, 28, 29, 32]. Many of these policies portray im/migrant sex workers as victims and purportedly aim to guard against exploitation [16, 22, 28, 32].

The merging of policies criminalising sex work and prohibitive immigration policies is used to justify the conflation of sex work with sex trafficking, often under the guise of protecting vulnerable im/migrants. However, this politicised conflation renders im/migrant sex workers susceptible to heightened scrutiny from police, immigration and municipal authorities, and generally takes the form of high levels of policing and surveillance over im/migrant sex workers' workspaces (e.g. massage parlours, micro-brothels) and even their homes [16, 29, 30, 33].

$\mathrm{Im} /$ migrant sex workers may be more likely to access third party services (e.g. venue managers, security, advertisers). They also frequently work together (i.e. as third parties to one another) and in managed in-call venues [34-36] to counter marginalisation related to im/migrant status, such as language barriers, barriers to finding clients, and low familiarity with the legal and labour context of the destination setting 
[22]. Concerningly, under legislative regimes that criminalise third parties with the purported goal of protecting sex workers from exploitation, managed indoor sex work spaces may face increased targeting by authorities. In Canada, anti-trafficking and police raids on indoor sex work venues have resulted in arrests, charges, and deportation of im/migrant sex workers [37-39]. Recent Canadian research found that $23.9 \%$ of 397 indoor sex workers had experienced a workplace inspection (by police, municipal, immigration, or health authorities), and 51.6\% worried about the potential consequences of these inspections, with recent im/migrant participants disproportionately affected by worry [33]. Although laws in Sweden and Norway state that 'victims of prostitution do not risk any legal repercussions' [29], im/migrant sex workers have faced harassment, discrimination, and forced evictions [28-30]. In Norway, police, accompanied by media, conducted raids of massage parlours, during which im/migrant sex workers' privacy was grossly violated through their exposure on national television [28].

In contrast to sex work laws and immigration policies depicting im/migrant sex workers as victims of violence and exploitation, current evidence suggests that some of the greatest harms facing im/migrant sex workers relate to these punitive laws and the enforcement thereof. This heavy burden of criminalisation has serious human rights implications, as evidence suggests that criminalisation, and enforcement and harassment by police, act to enhance workplace violence faced by sex workers [40, 41]. Punitive law enforcement also restricts workers' access to condoms and HIV/STI testing in the workplace [9, 42, 43], including workers' ability to carry condoms [44], thereby undermining broader HIV prevention and occupational health goals.

\section{Mandatory Health Testing: Punitive Regulations and Barriers to Health Services}

Prior research has documented how mandatory health testing can act as a form of surveillance of im/migrant sex workers [45, 46]. In the community consultations conducted for this chapter, im/migrant sex workers described the impacts of punitive mandatory sexual health testing and sex worker registration policies. In Austria, sex workers are required to undergo STI testing every 6 weeks, and HIV testing every 3 months. Sex workers with official registration are obliged to pay taxes and charges, but these are applied unequally across different provinces and brothels. Focus group participants described negative experiences with mandatory health testing centres, including poor treatment from health professionals and very limited health services. Even when im/migrant sex workers had other health concerns, these health centres did not offer other sexual or reproductive health or primary health services, and the health professionals refused to advise them. Participants perceived that numerous obligations were imposed onto sex workers to satisfy morality-based legal and health regulations, but that sex workers' own rights were barely taken into consideration. 


\begin{abstract}
Mandatory testing is based on the stereotype that sex workers are disproportionately responsible for spreading disease. It is a repressive tool, a way for the medical body and police who control if we get always have our card with stamps, proving that we are being checked regularly, to tell us what our place is and to maintain the social order-focus group participant
\end{abstract}

These participant experiences add to current evidence that criminalisation of and discrimination against im/migrant sex workers also occurs through im/migration and sex work regulation requirements (e.g. sex worker registration or licencing policies), and mandatory HIV/STI testing [45-47]. Research indicates that at the Mexico-Guatemala border, health authorities require sex workers to carry a health card (permit demonstrating routine HIV/STI testing at municipal health clinics) [45-47]. Im/migrant sex workers in this context expressed that these public health requirements were paired with punitive enforcement by local authorities, who used the process of verifying the im/migrant women's health cards as an opportunity to harass them $[45,46]$. In addition, many sex workers preferred not to maintain a health card due to privacy and immigration status concerns $[45,46]$. This finding echoes other research highlighting how mandatory registration and health testing regulations often create two 'tiers' of sex workers: those able to meet the imposed regulatory requirements, and those who cannot (e.g. due to precarious status, privacy and anonymity needs, or positive HIV/STI status). The latter tier are forced to work in a clandestine way, which increases their vulnerability to violence and exploitation $[16,48]$.

\title{
Precarious Immigration Status: Increasing Vulnerability and Barriers to Health and Police Protections
}

Consultation participants highlighted how immigration policies and sex work criminalisation intersected to increase vulnerability for im/migrants without full citizenship, reflecting current literature documenting vulnerability among sex workers with precarious im/migration status [16, 49, 50]. Sex workers in Austria described how any confrontation with police, arrests or charges could affect the next visa application. If im/migrant sex workers had unpaid fines for prostitution, they faced threats of deportation, regardless of whether they were EU citizens or not. This ongoing threat of loss of immigration status led im/migrant sex workers to avoid law enforcement interactions. Participants also highlighted that im/migrant sex workers often shared information on legal, immigration and labour issues with one another, addressing existing gaps in legal resources for im/migrants and sex workers by harnessing peer mentorship and support.

The term 'precarious immigration status' captures the many forms of 'less than full status', and is defined by the absence of key rights or entitlements associated with citizenship [51]. Those with precarious immigration status include 'documented' but temporary workers, students, and refugee applicants; people with unauthorised forms of status (e.g. visa overstayers, undocumented entrants) [52]; and 
individuals whose immigration status is rendered precarious through involvement in criminalised sex work. Current research shows that im/migrants with precarious status are more vulnerable to exploitation due to their heightened labour insecurity and risk of incarceration and deportation [2]. Among sex workers, having precarious status is a major determinant that shapes access to safe working conditions, health services (including HIV/STI testing and care), and police protections.

Our community consultations in Austria, and community reports and research from Canada and Europe suggest that, due to fear of police inspections and potential immigration status consequences $[9,16,22,53]$, im/migrant sex workers with precarious status are more likely to work in hidden environments (e.g. secluded, isolated street-based locations, private apartments), rather than in formal in-call venues (e.g. massage parlours). This has implications for the quality of their work environments and safety at work, as working in isolated areas renders sex workers more vulnerable to violent perpetrators and coercion into unprotected sex [29, 54-57]. Further, the ongoing threat of status revocation contributes to power imbalances between im/migrant sex workers, managers, and clients, which restrict sex workers' ability to negotiate supportive labour conditions and client condom use [9, 22].

Precarious status also restricts im/migrant sex workers from accessing HIV/STI testing and care. In a study in Italy, $100 \%$ of 345 mostly undocumented im/migrant sex workers confirmed that they had never previously been tested for HIV/STIs in Italy [58]. A study in Portugal found that gaps in testing and knowledge of testing services were greatest among undocumented sex workers [18], and recent studies from Somalia and Europe identified precarious status as a structural factor increasing im/migrant sex workers' vulnerability to HIV [18, 58, 59].

Despite prejudiced stereotypes regarding health status and HIV/STIs among im/ migrants, evidence suggests that im/migrants' health access and outcomes are shaped by restrictive and xenophobic immigration policies faced by marginalised $\mathrm{im} /$ migrants in destination settings $[60,61]$. These policies are particularly prohibitive among sex workers and those with precarious status. Precarious status has also been associated with heightened barriers to sexual and reproductive health services, and primary health care $[18,36,62-65]$.

Sex work involvement can increase im/migrants' precarity and result in heightened law enforcement surveillance and immigration status revocation. Community reports from Canada describe long-term detentions and deportations of im/migrant sex workers who had arrived via legal channels, but whose immigration status was rendered precarious through involvement in sex work-an activity uniquely criminalised for certain types of im/migrants under Canadian immigration policy [22]. As reflected in the experiences of our community consultation participants, precarious status also presents immense barriers to accessing police protection. In Hong Kong, $\mathrm{im} /$ migrant sex workers fear reporting violence due to concerns of facing deportation [66]. In France, where sex work clients are explicitly criminalised under enddemand laws, undocumented sex workers have faced police pressure and coercion to report clients, and threatened with deportation if they did not comply [53]. Sex workers with precarious status in Sweden, Norway, and the UK have faced surveillance by immigration authorities, threats of deportation, and deportations [28, 29, 
$57,67]$. There is strong evidence that fearing loss of immigration status motivates $\mathrm{im} /$ migrant sex workers to avoid interactions with authorities [22, 28, 29, 66, 68], which violates their rights to legal protections.

\section{Economic Marginalisation}

Financial vulnerability is a major determinant shaping labour environments and rights among sex workers globally. The community consultation participants asserted that economic marginalisation affected many im/migrant sex workers and increased their vulnerability at work. Furthermore, im/migrant status and sex work discrimination prevented them from accessing employment or the financial supports available to other people seeking work, such as employment agencies providing assistance to individuals who have legal status in Austria and are not engaged in sex work.

Globally, im/migrant workers in a wide range of industries face economic marginalisation in destination settings. Such marginalisation can be due to 'push' conditions in origin settings (e.g. poverty, family needs), expenses incurred during im/ migration, lower familiarity with the labour environment and employment options, language barriers, non-recognition of im/migrants' credentials (e.g. degrees, diplomas, certifications), and the need to financially support dependents or send remittances $[22,24,68]$. Economic marginalisation among im/migrant sex workers intersects with criminalisation, making their working conditions and health access precarious.

Financial vulnerability restricts the options available to im/migrant sex workers in terms of work environments, quality of clients, and the reliability of third parties. This limits their agency in accessing the most supportive work environments for themselves [69]. The community consultation participants emphasised how the social and economic marginalisation of im/migrant sex workers contributed to their vulnerability to exploitative working conditions and violations of labour rights, without any options for recourse.

One time he (sex work studio owner) took the keys from the door and told me that he will come back in 2 hours to close the studio. He didn't come back for the next 7 hours! And I had no choice; I had to wait for him!-focus group participant

Participants in our focus groups highlighted how the criminalisation of sex workenhanced im/migrant sex workers' economic marginalisation, isolated workers, maintained precarious labour conditions, and excluded the application of labour protections that could address exploitation at work. This finding reflects the experience of im/migrant sex workers in France, where shifting criminalisation has significantly increased economic vulnerability among the most marginalised sex workers, namely undocumented $\mathrm{im} /$ migrant women working in street-based locations [53]. 
Economic marginalisation can also enhance im/migrant sex workers' HIV and STI risk by reducing their ability to negotiate condom use with clients or to decline clients' offers of increased pay for unprotected sex [44, 69]. Finally, many general health, reproductive health, and HIV/STI services have high costs for im/migrants in destination settings, as im/migrants frequently do not enjoy legal entitlements to health care and are often excluded from utilising national healthcare services that are free/low-cost for citizens [70]. This results in many im/migrant sex workers deferring testing or treatment until a visit to their home country. Five different studies involving im/migrant sex workers from diverse contexts found that a significant proportion of im/migrants reported accessing sexual, reproductive health, and/or HIV/STI services in their country of origin, due to high costs and privacy concerns around using even free sexual health services in the destination country [44, 63, 71-73]. This raises concerns regarding delays in access to critical health services.

\section{Racialisation, Racism, Stigma, and Discrimination}

As with research documenting discriminatory treatment and lack of workplace protections among im/migrant workers in many industries [2, 4, 13], participants in community consultations reported that protections against labour discrimination enjoyed by Austrian sex workers and im/migrants from other EU countries are not afforded to sex workers from non-EU countries. With regard to employment, remuneration and working conditions, European Union labour laws prohibit discrimination against EU citizens based on their nationality. They further guarantee freedom of movement between EU countries, without discrimination based on citizenship. However, such protections are not in place for im/migrant sex workers from non-EU countries, who remain criminalised and without recourse for labour discrimination. Existing unemployment supports are also not extended, even to registered sex workers who pay tax.

I went to AMS [unemployment institution] because I'm not registered as a sex worker. So they don't have any idea that I'm a sex worker. But if I was registered sex worker who regularly paid all taxes, then after I stop working, I don't have any benefits from the system. That's terrible!-focus group participant

In addition to legal and labour discrimination against sex workers, im/migrant sex workers frequently face racism and racialised law enforcement in destination countries [16, 42]. Historically, sex workers have also been depicted as vectors for HIV/ STI transmission [20,74], and this stereotyping is particularly inflicted on racialised $\mathrm{im} /$ migrants and those from the Global South [19].

Across various contexts, racialised sex workers, including im/migrants, face discriminatory policing practices, such as police checking identification only among racialised/ethnic minority people, isolating racialised individuals for police questioning, and asking racialised women if they are being coerced or trafficked $[9,16$, $22,26,67]$. Xenophobic assumptions that portray im/migrant women as inherently 
vulnerable, likely to be victimised, and requiring state protection contribute to policies and programmes that aim to rescue im/migrant sex workers instead of provide rights-based supports for them [16, 22, 75].

$\mathrm{Im} /$ migrant sex workers can face a dual burden of stigma due to the intersection of two marginalised identities (i.e. im/migrant and sex worker), and this can be further compounded by race and ethnic background (e.g. Indigeneity) [76]. Isolation, sex work stigma, and socio-cultural stigmas surrounding sex contribute to privacy concerns when it comes to accessing health services and shape the preference of many im/migrant sex workers to neither disclose sex work involvement to their primary care provider nor to access sexual health testing from them [35, 36, 42, 63]. As asserted by our focus group participants and im/migrant sex workers in diverse countries, stigma and fear of poor treatment or discrimination by health professionals are powerful barriers to im/migrant sex workers' access to health care [36, 68, 73, 77], and further enhance their social exclusion.

\section{Language Barriers, Gender, and Power}

Language barriers faced by im/migrant sex workers in diverse settings can intersect with sex work criminalisation and precarious status to shape gendered power dynamics which impact sex workers' negotiations with police and clients $[9,16,35$, 44]. In community consultations, participants reported that language barriers and lack of familiarity with Austrian and EU laws contributed to worry and feelings of intimidation when police officers come to sex workers' workspaces, reflecting the experiences of other im/migrant sex workers across continents [50, 68, 78, 79]. They asserted that language barriers enhanced the power differentials between themselves and police, and contributed to poor treatment by police officers, as police often refused to speak in English during investigations. In contrast, im/ migrant sex workers with strong spoken German and who had obtained Austrian citizenship reported better treatment from Austrian police officers, illustrating discrimination based on language abilities and immigration status.

Mirroring the experiences of our community consultation participants, research from other Global North contexts has found that language interpreters are rarely available during police raids and inspections of indoor venues where im/migrant sex workers work, and that language barriers contribute to intimidation and fear [22, 26, 80]. Furthermore, criminalisation, gendered power dynamics, and language barriers can intersect to undermine the ability of im/migrant workers to negotiate condom use. For example, in Canada, im/migrant women sex workers reported recognition of their limited proficiency in English, and of gendered power imbalances between themselves and clients. They cited having to 'be accommodating' to clients' requests (i.e. for condomless services), due to fears that an unsatisfied client may draw police attention [9]. In another study involving im/migrant sex workers in Canada, 58\% of 129 sex workers had ever had a client try to pull/sneak a condom off during sex [35], while im/migrant sex workers in Moscow reported incidents of violence and physi- 
cal force from aggressors who coerced the worker into providing sex without condoms [44]. This evidence highlights how language barriers can heighten vulnerability among im/migrant sex workers in interactions with police and clients, restricting their agency and compounding their marginalisation.

\section{Unique Marginalisation of Male and Gender-Diverse Im/ migrant Sex Workers}

Research into and discourse around trafficking have contributed to prominent misrepresentations of im/migrant sex workers as women with low levels of agency who are coerced into sexual labour [19-22]. These paternalistic representations contribute to the erasure of male and gender-diverse sex workers, and justify high levels of policing and im/migration enforcement among im/migrants.

In addition to sex work stigma, male im/migrant sex workers can face a burden of homophobia, particularly in countries which criminalise and police same-sex practices [78]. Researchers have also noted that men who have paid sex are less likely to self-identify as sex workers and often remain hidden by arranging sex service encounters via the internet, and are therefore missed by typical public health interventions targeting this group [81]. While high rates of physical and sexual violence, heavy HIV and STI burdens, discrimination, and barriers to health services have been documented among transgender sex workers across continents [78], very limited literature has documented the experiences of male and gender-diverse im/ migrant sex workers, highlighting a need for further research exploring how gender intersects with im/migrant status among sex workers to shape health access and labour rights.

\section{Recommendations and Areas for Intervention}

The preceding sections have illustrated how, on a global level, labour conditions and health access among im/migrant sex workers are shaped by: criminalisation, mandatory health testing, and registration policies; precarious status, economic marginalisation, racialisation, racism, stigma, and discrimination; language barriers, and gender. To date, most evidence-based approaches to promoting health and rights among sex workers globally are based on information from, and research involving, non-im/migrant sex workers. There are only limited peer-reviewed intervention studies or best practice guidelines specifically for migrants, with exceptions including policy documents from NSWP and ICRSE [79, 82]. However, research involving im/ migrant sex workers in diverse global settings and the community consultations for this chapter demonstrate the need for structural interventions including health-promoting laws and policies, work environment factors (i.e. supportive management, 
condom access, HIV/STI services, and sexual health education in the workplace), and community empowerment determinants (i.e. peer support). With these in place, it is possible to enhance labour rights and promote health access among im/migrant sex workers.

\section{Enabling Indoor Work Environments}

Formal indoor work venues represent key opportunities or sites for interventions designed to promote im/migrant sex workers' access to health services [35, 69]. In contexts where laws and policies enable the distribution of condoms within indoor sex work spaces, sex workers have reported consistent access to condoms, which supports consistent condom use. In Mali, where HIV prevention programmes for sex workers (including condom provision and promotion) have been a government priority since 1987, 99\% of im/migrant sex workers surveyed in 2009 reported having access to condoms in the workplace, and approximately $97 \%$ reported consistent condom use with clients in the past month [83]. Given that criminalised conditions constrain indoor venues from openly selling sexual services and restrict sex work managers from distributing condoms in these spaces, legislative reforms towards decriminalising all aspects of sex work, including third parties, are recommended to enable supportive labour environments for sex workers.

Supportive third parties, access to condoms, and access to sexual health services and education in the workplace have been documented to promote effective negotiation of condom use and enable increased uptake of HIV/STI testing among im/ migrant sex workers in several global settings [45, 69, 83, 84]. As previously described, im/migrant sex workers may also benefit from legal access to third party services (e.g. administrative support, advertising, security). Third party support has been identified by sex workers across continents as a critical facet of HIV prevention [85]. Among im/migrant and non-im/migrant sex workers in Canada, the use of third party administrative and security services was recently linked to heightened access to mobile condom distribution and sex worker-led services [86]. Our findings suggest that constructive interventions are those that (1) implement laws and policies aimed at enhancing health access among im/migrant sex workers and (2) enable the legal operation of formal indoor sex work venues and support their management in promoting sexual health [86].

\section{Removal of Punitive Laws and Policies}

There is a critical need for law reforms that decriminalise all aspects of sex work and enable sex workers to legally access supportive workspaces and third parties, in order to create the most optimal working conditions and choices for themselves. Current evidence on the harms of sex work criminalisation, and community-based 
calls for the removal of punitive laws align with the recommendations of international policy institutions, including the WHO, UNAIDS, UNDP, and Amnesty International, who call for the full decriminalisation of all aspects of sex work as necessary to promote the human rights of sex workers [87-90]. In considering law reforms, participants in the community consultations highlighted that the meaningful involvement of diverse groups of sex workers in legislation, policy, and programme design was paramount to ensure that laws, regulations, and health promotion interventions reflect the needs and lived experiences of diverse im/migrant sex workers worldwide, contributing to the enhancement of their health and human rights.

Importantly, international policy bodies, including UNAIDS and WHO, have acknowledged that mandatory health testing and registration requirements violate the human rights of sex workers [78]. Repressive HIV prevention approaches, such as mandatory health testing and sex worker registration, present serious concerns, as these are often coercive and may result in exclusion from services among the most marginalised im/migrants. Our community consultation participants also denounced mandatory HIV/STI testing, asserting that such policies reinforce harmful and inaccurate representations of sex workers as vectors for disease, and called for rightsbased and community-led approaches to increasing health access.

\section{Supporting Peer and Community-Led Education, Outreach, and Services}

Community consultation participants emphasised an urgent need for im/migrant sex worker-led programmes, such as peer-to-peer education, to enhance workers' knowledge of their legal and labour rights and to promote their access to health services. They also highlighted the importance of safe spaces, such as drop-in centres, where im/migrant sex workers can access supports without fear of police or immigration enforcement. Current evidence illustrates that peer-based and community-led interventions delivered in indoor sex work venues and to street-based environments help to mitigate the pervasive structural and migration-related barriers to appropriate health services. This suggests a need to expand community-led services, with language supports and which are culturally appropriate to participants, in spaces where im/migrant sex workers are comfortable [35, 69, 91].

Rather than enforcement-based approaches, im/migrant sex workers from diverse settings have expressed a need for, and appreciation of, community-led outreach services which offer sexual health resources (i.e. condoms, lubricants), voluntary sexual health testing, and private/anonymous, nonjudgmental sexual health nursing $[35,42,63,69,91]$. This transition from punitive to supportive approaches emphasises the rights of im/migrant sex workers, and prioritises community-based health promotion to ensure timely, accessible, and appropriate health services for im/ migrant sex workers globally. 


\section{Conclusion}

In this chapter, we have highlighted the structural and migration-related barriers to labour rights and health access faced by im/migrant sex workers everywhere. Criminalisation, precarious status, economic marginalisation, and intersecting forms of exclusion based on race, gender, and immigration status represent powerful determinants that restrict im/migrant sex workers from fair access to health services and labour rights.

Our literature review and community consultations also challenge prominent stereotypes about im/migrant sex workers as a marginalised, victimised group. The fact that im/migrant sex workers across diverse global contexts continue to access health services, practice safer sex, work together, share legal, labour and health resources, and travel to get their health needs met-even in the face of layered criminalisation and persistent migration-related barriers-speaks to their resistance to structural oppression and their strong agency. In contrast to prominent frames of $\mathrm{im} /$ migrant sex workers as passive victims, current research portrays im/migrant sex workers as tenacious, active, and goal-oriented workers.

The community consultation participants asserted that supporting im/migrant sex worker-led action and advocacy were top priorities in the struggle to uphold their rights. Their lived experiences, community reports, and current research suggest a need to build on existing community-led interventions. Finally, it is critical to work towards reforming laws criminalising sex work and to address punitive policing and im/migration enforcement. If we are to promote im/migrant sex workers' access to health services and affirm their labour rights, this work can only be undertaken effectively in collaboration with im/migrant sex workers as experts in their own lives and experiences.

\section{References}

1. Smith PM, Mustard CA. The unequal distribution of occupational health and safety risks among immigrants to Canada compared to Canadian-born labour market participants: 19932005. Saf Sci. 2010;48(10):1296-303.

2. Benach J, Muntaner C, Delclos C, Menéndez M, Ronquillo C. Migration and "low-skilled" workers in destination countries. PLoS Med. 2011;8(6):e1001043.

3. Hasstedt K. Toward equity and access: removing legal barriers to health insurance coverage for immigrants. Guttmacher Policy Rev. 2013;16(1):2-8.

4. Holmes S. Fresh fruit, broken bodies. Migrant farmworkers in the United States. Berkeley: University of California Press; 2013.

5. Moyce SC, Schenker M. Migrant workers and their occupational health and safety. Annu Rev Public Health. 2018;39:351-65.

6. Lucchini RG, London L. Global occupational health: current challenges and the need for urgent action. Ann Glob Health. 2014;80(4):251-6.

7. Pérez ER, Benavides FG, Levecque K, Love JG, Felt E, Van Rossem R. Differences in working conditions and employment arrangements among migrant and non-migrant workers in Europe. Ethn Health. 2012;17(6):563-77. 
8. Woodward A, Howard N, Wolffers I. Health and access to care for undocumented migrants living in the European Union: a scoping review. Health Policy Plan. 2014;29:818-30.

9. Goldenberg SM, Krüsi A, Zhang E, Chettiar J, Shannon K. Structural determinants of health among im/migrants in the indoor sex industry. PLoS One. 2017;12(1):e0170642.

10. Oxman-Martinez J, Hanley J, Lach L, Khanlou N, Weerasinghe S, Agnew V. Intersection of Canadian policy parameters affecting women with precarious immigration status: a baseline for understanding barriers to health. J Immigr Health. 2005;7(4):247-58.

11. Harcourt W, Escobar A. Introduction practices of difference: introducing woman and the politics of place. In: Woman and the politics of place. Bloomfield, CT: Kumarian Press; 2005.

12. Benach J, Vives A, Amable M, Vanroelen C, Tarafa G, Muntaner C. Precarious employment: understanding an emerging social determinant of health. Annu Rev Public Health. 2014;35(1):229-53.

13. Premji S, Spasevski M, Athar S, Shakya Y, Merolli J, et al. Precarious work experiences of racialized immigrant women in Toronto: a community-based study. Just Labour. 2014;22:122-43.

14. Lewis H, Dwyer P, Hodkinson S, Waite L. Hyper-precarious lives. Prog Hum Geogr. 2015;39(5):580-600.

15. Castles S. Migration, precarious work, and rights. In: Migration, precarity, and global governance: challenges and opportunities for labour. Oxford: Oxford University Press; 2015. p. 46-67.

16. Vuolajärvi N. Governing in the name of caring - the Nordic model of prostitution and its punitive consequences for migrants who sell sex. Sex Res Soc Policy. 2019;16:151-65.

17. Baye EMO, Heumann S. Migration, sex work and exploitative labor conditions: experiences of Nigerian women in the sex industry in Turin, Italy, and counter-trafficking measures. Gend Technol Dev. 2014; https://doi.org/10.1177/0971852413515322.

18. Dias S, Gama A, Pingarilho M, Simões D, Mendão L. Health services use and HIV prevalence among migrant and National female sex workers in Portugal: are we providing the services needed? AIDS Behav. 2017;21(8):2316-21.

19. Brock D, Gillies K, Oliver C, Sutdhibhasilp M. Migrant sex work - a roundable, Canadian woman studies, vol. 20. Toronto, ON: York University; 2000.

20. Mårdh P-A, Genç M. Migratory prostitution with emphasis on Europe. J Travel Med. 1995; https://doi.org/10.1111/j.1708-8305.1995.tb00616.x.

21. Andrijasevic R. Beautiful dead bodies: gender, migration and representation in anti-trafficking campaigns. Fem Rev. 2007;86(1):24-44.

22. Lam E. Behind the rescue: how anti-trafficking investigations and policies harm migrant sex workers. Toronto: Butterfly Asian and Migrant Sex Workers Support Network; 2018.

23. Goldenberg SM, Liu V, Nguyen P, Chettiar J, Shannon K. International migration from non-endemic settings as a protective factor for HIV/STI risk among female sex workers in Vancouver, Canada. J Immigr Minor Health. 2015;17(1):21-8.

24. Platt L, Grenfell P, Fletcher A, Sorhaindo A, Jolley E, Rhodes T, et al. Systematic review examining differences in HIV, sexually transmitted infections and health-related harms between migrant and non-migrant female sex workers. Sex Transm Infect. 2013;89(4):311-9.

25. TAMPEP. Position Paper - CEDAW [Internet]; 2019.

26. Lam E. Inspection, policing, and racism: how municipal by-laws endanger the lives of Chinese sex workers in Toronto. Can Rev Soc Policy. 2016;75:87-112.

27. Lam E. Shutting down massage parlours: anti-trafficking, or anti-migration? In: Law and Society Association Annual Meeting. Washington DC; 2019.

28. PION. CEDAW 2017 - Shadow report by PION [Internet]; 2017.

29. Levy J, Jakobsson P. Sweden's abolitionist discourse and law: effects on the dynamics of Swedish sex work and on the lives of Sweden's sex workers. Criminol Crim Justice. 2014;14(5):593-607.

30. Amnesty International. Criminalization of sex work in Norway: the human cost of "crushing" the market [Internet]. 
31. Abel G. Dignity in choice: the illegal status of migrant sex workers in new Zealand. In: Law and Society Association Annual Meeting. Washington DC; 2019.

32. Government of Canada. Immigration and refugee protection regulations [Internet]. Ottawa. 2018. http://laws-lois.justice.gc.ca.

33. McBride B, Shannon K, Duff P, Mo M, Braschel M, Goldenberg SM. Harms of workplace inspections for im/migrant sex workers in in-call establishments: enhanced barriers to health access in a Canadian Setting. J Immigr Minor Health. 2019;21(6):1290-9.

34. Autres Regards. Outreach in indoor sex work settings 2013-2014 indoors - empowerment and skill building tools for national and migrant female sex workers working in hidden places [Internet]. Marseille; 2014.

35. Bungay V, Kolar K, Thindal S, Remple VP, Johnston CL, Ogilvie G. Community-based HIV and STI prevention in women working in indoor sex markets. Health Promot Pract. 2013;14(2):247-55.

36. Selvey LA, Lobo RC, McCausland KL, Donovan B, Bates J, Hallett J. Challenges facing Asian sex workers in Western Australia: implications for health promotion and support services. Front Public Health. 2018;6:171.

37. Leblanc S. Milton massage parlour raid leads to charges. Hamilton Spectator [Internet]; 2016.

38. Yogaretnam S. Police raid residential erotic massage parlour: 76 human trafficking charges for alleged ringleader. The National Post [Internet]; 2015.

39. Hempstead D. 11 women face possible deportation after massage parlour raids. Ottawa Sun [Internet]; 2015.

40. Deering KN, Amin A, Shoveller J, Nesbitt A, Garcia-Moreno C, Duff P, et al. A systematic review of the correlates of violence against sex workers. Am J Public Health. 2014;104(5):42-54.

41. Prakash R, Manthri S, Tayyaba S, Joy A, Raj SS, Singh D, et al. Effect of physical violence on sexually transmitted infections and treatment seeking behaviour among female sex workers in Thane District, Maharashtra, India. PLoS One. 2016;11(3):1-20.

42. Anderson S, Shannon K, Li J, Lee Y, Chettiar J, Goldenberg S, et al. Condoms and sexual health education as evidence: impact of criminalization of in-call venues and managers on migrant sex workers access to HIV/STI prevention in a Canadian setting. BMC Int Health Hum Rights. 2016;16(1):1-10.

43. Lim RBT, Cheung ONY, Tham DKT, La HH, Win TT, Chan R, et al. Using qualitative and community-based engagement approaches to gain access and to develop a culturally appropriate STI prevention intervention for foreign female entertainment workers in Singapore. Glob Health. 2018;14(1):36.

44. Weine S, Golobof A, Bahromov M, Kashuba A, Kalandarov T, Jonbekov J, et al. Female migrant sex workers in Moscow: gender and power factors and HIV risk. Women Health. 2013;53(1):56-73.

45. Goldenberg SM, Rocha Jimenez T, Brouwer KC, et al. Influence of indoor work environments on health, safety, and human rights among migrant sex workers at the Guatemala-Mexico Border: a call for occupational health and safety interventions. BMC Int Health Hum Rights. 2018;18(1):9.

46. Jiménez TR, Brouwer KC, Silverman JG, Morales-Mirand S, Goldenberg SM. Exploring the context and implementation of public health regulations governing sex work: a qualitative study with migrant sex workers in Guatemala. J Immigr Minor Health. 2017;19(5):1235-44.

47. Rocha-Jimenez T, Morales-Miranda S, Fernandez-Casanueva C, Brouwer KC. The influence of migration in substance use practices and HIV/STI-related risks of female sex workers at a dynamic border crossing. J Ethn Subst Abuse. 2020;19(4):503-20.

48. Global Network of Sex Work Projects. Sex work and the law: understanding legal frameworks and the struggle for sex work law reforms [Internet]; 2019.

49. Goldenberg SM. Trafficking, migration, and health: complexities and future directions. Lancet Glob Health. 2015;3:e118-9. 
50. Butterfly Asian and Migrant Sex Workers Support Network. Behind the rescue: how antitrafficking investigations and policies harm migrant sex workers. Toronto: Butterfly Asian and Migrant Sex Workers Support Network; 2018.

51. Goldring L, Landolt P. Caught in the work-citizenship matrix: the lasting effects of precarious legal status on work for Toronto immigrants. Globalizations. 2011;8:325-41.

52. Goldring L, Berinstein C, Bernhard JK. Institutionalizing precarious migratory status in Canada. Citizenship Stud. 2009;13(3):239-65.

53. Le Bail H, Giametta C. What do sex workers think about the French prostitution act?; 2018.

54. Oppal WT. Forsaken: the report of the Missing Women Commission of Inquiry Executive Summary [Internet]. Vancouver; 2012.

55. Krüsi A, Pacey K, Bird L, Taylor C, Chettiar J, Allan S, et al. Criminalisation of clients: reproducing vulnerabilities for violence and poor health among street-based sex workers in Canada-a qualitative study. BMJ Open. 2014;4(6):e005191.

56. NSWP. The impact of criminalisation on sex workers' vulnerability to HIV and violence [Internet]; 2017.

57. Klambauer E. Policing roulette: sex workers' perception of encounters with police officers in the indoor and outdoor sector in England. Criminol Crim Justice. 2018;18(3):255-72.

58. Zermiani M, Mengoli C, Rimondo C, Galvan U, Cruciani M, Serpelloni G. Prevalence of sexually transmitted diseases and hepatitis $\mathrm{C}$ in a survey of female sex workers in the North-East of Italy. Open AIDS J. 2012;6(1):60-4.

59. Kriitmaa K, Testa A, Osman M, Bozicevic I, Riedner G, Malungu J, Irving G, Abdalla I. HIV prevalence and characteristics of sex work among female sex workers in Hargeisa, Somaliland, Somalia. AIDS. 2010;24(Suppl 2):S61-7.

60. European Center for Disease Prevention and Control. Migrant health: epidemiology of HIV and AIDS in migrant communities and ethnic minorities in EU/EEA countries; 2010.

61. Mahon C. Most HIV-positive migrants in Europe acquired HIV post-migration I AVERT. Avert; 2017.

62. Campbell RM, Klei AG, Hodges BD, Fisman D, Kitto S. A comparison of health access between permanent residents, undocumented immigrants and refugee claimants in Toronto, Canada. J Immigr Minor Health. 2014;16(1):165-76.

63. Darling KEA, Gloor E, Ansermet-Pagot A, Vaucher P, Durieux-Paillard S, Bodenmann P, et al. Suboptimal access to primary healthcare among street-based sex workers in Southwest Switzerland. Postgrad Med J. 2013;89(1053):371-5.

64. Richter M, Chersich MF, Vearey J, Sartorius B, Temmerman M, Luchters S. Migration status, work conditions and health utilization of female sex workers in three South African cities. J Immigr Minor Health. 2014;16(1):7-17.

65. Davis A, Meyerson BE, Aghaulor B, Brown K, Watson A, Muessig KE, et al. Barriers to health service access among female migrant Ugandan sex workers in Guangzhou, China. Int J Equity Health. 2016;15(1): 170.

66. Wong WCW, Holroyd E, Bingham A. Stigma and sex work from the perspective of female sex workers in Hong Kong. Sociol Health Illn. 2011;33(1):50-65.

67. Jahnsen S, Skilbrei ML. Leaving no stone unturned: the borders and orders of transnational prostitution. Br J Criminol. 2018;58(2):255-72.

68. Goldenberg SM, Krusi A, Zhang E, Chettiar J, Shannon K. Structural determinants of health among im/migrants in the indoor sex industry. PLoS One. 2017;12:e0170642.

69. Febres-Cordero B, Brouwer KC, Rocha-Jimenez T, Fernandez-Casanueva C, Morales-Miranda S, Goldenberg SM. Influence of peer support on HIV/STI prevention and safety amongst international migrant sex workers: a qualitative study at the Mexico-Guatemala border. PLoS One. 2018;13(1):e0190787.

70. Rechel B, Mladovsky P, Ingleby D, Mackenbach JP, McKee M. Migration and health in an increasingly diverse Europe. Lancet. 2013;381(9873):1235-45. 
71. Platt L, Grenfell P, Bonell C, Creighton S, Wellings K, Parry J, et al. Risk of sexually transmitted infections and violence among indoor-working female sex workers in London: the effect of migration from Eastern Europe. Sex Transm Infect. 2011;87(5):377-84.

72. Wong M-L, Chan R, Tan HH, Yong E, Lee L, Cutter J, et al. Sex work and risky sexual behaviors among foreign entertainment workers in urban Singapore: findings from mystery client survey. J Urban Health. 2012;89(6):1031-44.

73. Rocha-Jimenez T, Morales-Miranda S, Fernandez-Casanueva C, Brouwer KC, Goldenberg SM. Stigma and unmet sexual and reproductive health needs among international migrant sex workers at the Mexico-Guatemala border. Int J Gynaecol Obstet. 2018;143(1):37-43.

74. van Haastrecht HJ, Fennema JS, Coutinho RA, van der Helm TC, Kint JA, van den Hoek JA. HIV prevalence and risk behaviour among prostitutes and clients in Amsterdam: migrants at increased risk for HIV infection. Sex Transm Infect. 2008;69(4). https://doi.org/10.1136/ sti.69.4.251

75. Global Network of Sex Work Projects. The impact of "end demand" legislation on women sex workers - POLICY BRIEF; 2018.

76. Taran P. Migrant women, women migrant workers - crucial challenges for rights-based action and advocacy. In: OHCHR-UNWOMEN side event to 64th Session of the UN Committee on the Elimination of Discrimination Against Woment (CEDAW): "Promoting and Protecting Women Migrant Workers' Labour and Human Rights through CEDAW and CMW" [Internet]. Geneva; 2016.

77. Scorgie F, Nakato D, Harper E, Richter M, Maseko S, Nare P, et al. "We are despised in the hospitals": sex workers' experiences of accessing health care in four African countries. Cult Health Sex. 2013;15(4):450-65.

78. UNAIDS. The gap report - sex workers. Geneva: UNAIDS; 2014.

79. NSWP. Migrant sex workers BRIEFING PAPER [Internet]; 2018.

80. SWAN Vancouver Society. Im/migrant sex workers, myths and misconceptions: realities of the anti-trafficked. Vancouver: SWAN Vancouver Society; 2015.

81. Verhaegh-Haasnoot A, Dukers-Muijrers NHTM, Hoebe CJPA. High burden of STI and HIV in male sex workers working as internet escorts for men in an observational study: a hidden key population compared with female sex workers and other men who have sex with men. BMC Infect Dis. 2015;15(1):291.

82. International Committee on the Rights of Sex Workers in Europe. Policy brief and recommendations on the rights of migrant sex workers [Internet]; 2016.

83. Trout CH, Dembélé O, Diakité D, Bougoudogo F, Doumbia B, Mathieu J, et al. West African female sex workers in Mali. J Acquir Immune Defic Syndr. 2015;68:S221-31.

84. Lim RBT, Cheung ONY, Tai BC, Chen MI-C, Chan RKW, Wong ML. Efficacy of multicomponent culturally tailored HIV/STI prevention interventions targeting foreign female entertainment workers: a quasi-experimental trial. Sex Transm Infect. 2018;94(6):449-56.

85. Goldenberg SM, Duff P, Krusi A. Work environments and HIV prevention: a qualitative review and meta-synthesis of sex worker narratives. BMC Public Health. 2015;15(1):1241.

86. McBride B, Goldenberg SM, Murphy A, Wu S, Braschel M, Krüsi A, et al. Third parties (venue owners, managers, security, etc.) and access to occupational health and safety among sex workers in a Canadian setting: 2010-2016. Am J Public Health. 2019;109:792-8.

87. WHO. Consolidated guidelines on HIV prevention, diagnosis, treatment and care for key populations - 2016 update. Geneva: WHO; 2016.

88. UNAIDS. The gap report 2014 - sex workers. Geneva: UNAIDS; 2014.

89. Godwin J. Sex work and the law in Asia and the Pacific - laws, HIV and human rights in the context of sex work [internet]. Bangkok; 2012.

90. Amnesty International. Decision on state obligations to respect, protect, and fulfil the human rights of sex workers. Int Counc Decis; 2016. p. 9-10.

91. Deering KN, Montaner JS, Chettiar J, Jia J, Ogilvie G, Buchner C, et al. Successes and gaps in uptake of regular, voluntary HIV testing for hidden street- and off-street sex workers in Vancouver, Canada. AIDS Care. 2015;27(4):499-506. 
Open Access This chapter is licensed under the terms of the Creative Commons Attribution 4.0 International License (http://creativecommons.org/licenses/by/4.0/), which permits use, sharing, adaptation, distribution and reproduction in any medium or format, as long as you give appropriate credit to the original author(s) and the source, provide a link to the Creative Commons license and indicate if changes were made.

The images or other third party material in this chapter are included in the chapter's Creative Commons license, unless indicated otherwise in a credit line to the material. If material is not included in the chapter's Creative Commons license and your intended use is not permitted by statutory regulation or exceeds the permitted use, you will need to obtain permission directly from the copyright holder. 